Revista Brasileira de Farmacognosia Brazilian Journal of Pharmacognosy 21(6): 1104-1110, Nov./Dec. 2011

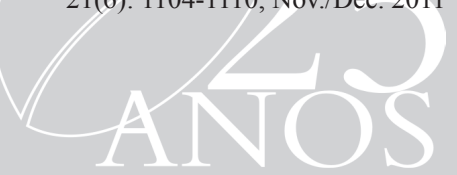

Article

Received 9 Nov 2010

Accepted 8 Jun 2011

Available online 9 Sep 2011

Keywords:

lipid peroxidation

nitrite

pilocarpine

P. insignis

seizures

ISSN 0102-695X

http://dx.doi.org/10.1590/S0102

$695 \mathrm{X} 2011005000163$

\section{Evaluation of effects of dichloromethane fraction from Platonia insignis on pilocarpine- induced seizures}

\author{
Joaquim S. da Costa Júnior, ${ }^{1}$ Alexandre de B. F. Ferraz, ${ }^{1}$ \\ Chistiane Mendes Feitosa, ${ }^{2}$ Antonia Maria das Graças Lopes \\ Citó, ${ }^{2}$ Jenifer Saffi, ${ }^{3}$ Rivelilson Mendes de Freitas ${ }^{*}, 4$
}

\author{
${ }^{1}$ Laboratório de Toxicologia Genética, Programa de Pós-graduação em Toxicologia \\ Genética e Aplicada, Universidade Luterana do Brasil, Brazil, \\ ${ }^{2}$ Departamento de Química, Instituto Federal do Piaui, Brazil, \\ ${ }^{3}$ Departamento de Ciências Básicas da Saúde, Universidade Federal de Ciências da \\ Saúde de Porto Alegre, Brazil, \\ ${ }^{4}$ Departamento de Bioquímica e Farmacologia, Instituto Federal do Piaui, Brazil.
}

\begin{abstract}
The objective of present study was to evaluate the antioxidant and anticonvulsant activities of dichloromethane fraction (DMF) from Platonia insignis Mart., Clusiaceae. The DMF from P. insignis $(2 \mathrm{mg} / \mathrm{kg}$ ) was tested by intraperitoneal (i.p.) to evaluate effects on lipid peroxidation level, nitrite formation, as well as on locomotor and anticonvulsant activities. Wistar rats were treated with, (saline/ Tween 80 0.5\%, i.p., control group), DMF ( $2 \mathrm{mg} / \mathrm{kg}$, i.p., DMF group), pilocarpine $(400 \mathrm{mg} / \mathrm{kg}$, i.p., P400 group), or the combination of DMF $(2 \mathrm{mg} / \mathrm{kg}$, i.p.) and pilocarpine $(400 \mathrm{mg} / \mathrm{kg}$, i.p., DMF plus P400). After the treatments all groups were observed for $24 \mathrm{~h}$. In P400 group rats there was a decrease in the motor activity when compared with control group. In DMF plus P400 co-administered rats was observed an increase in motor activity when compared with P400 group. In P400 group rats there was a significant increase in lipid peroxidation and nitrite levels. In DMF plus P400 co-administered rats, antioxidant treatment significantly reduced the lipid peroxidation level and nitrite content after seizures. Previous findings strongly support the hypothesis that oxidative stress occurs in rat striatum during pilocarpine-induced seizures, and our results imply that strong neuprotective effect on this brain region could be achieved using DMF from $P$. insignis.
\end{abstract}

\section{Introduction}

Medicinal plants play a key role not only in selfmedication but also in medical practice of the wild world. The power of the chemical and biochemical techniques in studying such plants has led to discovery of important agents for treatment of long-last diseases. These discoveries emphasize the pharmaceutical potential of the medicinal plants (Bezerra et al., 2008).

The term epilepsy is collectively designated for a group of chronic central nervous system disorders characterized by spontaneous occurrence of seizures generally associated with the loss of consciousness and body movements of convulsions (Chauhan et al., 1988). The search for antiepileptic compounds with more selective activity and lower toxicity continues to be an area of intensive investigation in medicinal chemistry (Malawska, 2005). Various phytochemical and pharmacological studies have been carried out on these anticonvulsant plants (Quintans Júnior et al., 2008a).

Platonia insignis Mart., Clusiaceae, commonly known as "bacuri", is a thick-skinned fruit, with approximate dimension of an orange, which contains a large quantity of resins. The pulp enclosing the seeds is white, bittersweet, with a pleasant smell and taste. The fruit can be consumed raw or in the form of juice, icecream or jam (Alves \& Jennings, 1979). A number of xanthone have been isolated from plants belonging to this family (Ollis et al., 1965).

Many new polyisoprenylated benzophenones with a bicycle-[3.3.1]-nonane-2,4,9-trione core structure have been isolated from plants in the Clusiaceae family, and their potent biological properties have been the subject of several studies. This review summarizes the biological activities reported for these secondary metabolites including cytotoxic, antimicrobial, antioxidant, and 
anti-inflammatory activities (Acuna et al., 2009; Costa Júnior et al., 2011). The polycyclic polyprenylated acylphloroglucinols exhibit a wide variety of biological activities such as antimicrobial, antidepressant, antioxidant, cytotoxic, and antiviral activities (Ciochina \& Grossman, 2006).

The fats form the $P$. insignis seeds (bacuri fat) are yellowish solid rich in triacylglycerols and fatty acid (Bentes et al., 1986). The composition of bacuri fat, the seed fat of $P$. insignis and found that its chief component acids are palmitic and oleic acid, with smaller proportions of stearic and palmitoleic acids and probably traces of myristic, arachidic, and linoleic acids.

Omega-3 and omega-6 polyunsaturated fatty acids (PUFA) are dietary fatty acids that are involved in a myriad of physiologic processes in the brain. There is some evidence suggesting that PUFA and particularly omega-3 PUFA may have anticonvulsant effects, both in humans and animals (Taha et al., 2010).

Natural xanthones have been reported in genera Calophyllum, Platonia, Symphonia, and Kielmeyera (Jackson et al., 1966). A series of xanthone derivatives have shown pronounced anticonvulsant activity (Marona et al., 2001; Marona et al., 2008). The aim of present study was to examine the effects of DMF from $P$. insignis on lipid peroxidation level and nitrite formation in rat striatum, as well as research their anticonvulsant activity in adult rats prior to pilocarpine-induced seizures.

\section{Materials and methods}

\section{Drugs}

The drugs used pilocarpine hydrochloride, trichloroacetic acid, thiobarbituric acid, sodium nitrite, and polyoxyethylene-sorbitan monolated (Tween 80) were purchased from Sigma (USA). Agents were administrated by intraperitoneally (i.p.) route at a dose volume of $0.1 \mathrm{~mL} / 10 \mathrm{~g}$.

Plant material and preparation of DMF from $\mathrm{P}$. insignis

The Platonia insignis Mart., Clusiaceae, fruits were collected at Barras, Piauí State, Brazil, in March 2009. A voucher specimen has been identified and deposited at the "Graziela Barroso", Herbarium of Biology Department of Federal University of Piauí, Brazil (Voucher No.: ICN TEPB 27.164). The seeds collected from the fruits of $P$. insignis were dried at $55{ }^{\circ} \mathrm{C}$ under shade and powdered mechanically. Crush yielded of seeds (848 g) was extracted with n-hexane $(63 \%, \mathrm{w} / \mathrm{w})$, followed by $95 \%$ ethanol $(5.8 \%, \mathrm{w} / \mathrm{w})$ in a Soxhlet apparatus ( $8 \mathrm{~h}$ for each solvent). In the ethanol extract it was added $100 \mathrm{~mL}$ of water, which was then fractionated using polarity increasing solvents. The ethanol extract was fractionated with dichloromethane (8 x $100 \mathrm{~mL}$ ) to obtain a dichloromethane soluble fraction. The fraction was concentrated in a vacuum evaporator. The concentrated extract was finally freeze-dried to get the yield of 3.4\% of DMF. The dried extract was kept at $4{ }^{\circ} \mathrm{C}$ in refrigerator in the air tight bottles until use.

\section{Animals and treatment protocols}

Adult male Wistar rats $(250-280 \mathrm{~g})$ were maintained in a temperature controlled room $\left(26 \pm 1{ }^{\circ} \mathrm{C}\right)$ with a 12-h light/dark cycle and food and water ad libitum (Nutrilabor, Campinas, Brazil). All experiments were performed according to the guide for the care and use of laboratory the US Department of Health and Human Services, Washington, DC (1985).

A total of 96 rats were treated with either $2 \mathrm{mg} /$ kg DMF from P. insignis (i.p., DMF) or vehicle (saline/ Tween $800.5 \%$, i.p.), and $30 \mathrm{~min}$ later the treatments 24 rats from each above group were randomized to pilocarpine hybrochloride administration (400 mg/kg, i.p., P400). Thus there are four groups of rats in this set of experiments: group 1, DMF and P400 co-administration $(\mathrm{n}=24)$; group 2, P400 plus vehicle treatment $(\mathrm{n}=24)$; group 3, DMF alone administration $(n=24)$; and group 4 , vehicle treatment serves as control $(n=24)$. After the treatments, the animals were recorded in $30 \mathrm{~cm} \mathrm{x} 30 \mathrm{~cm}$ chambers with: latency to first seizure (any one of the behavioral indices typically observed after pilocarpine administration: wild running, clonuses, tonus, clonictonic seizures) and number of animals that died after pilocarpine administration. Previous work has shown that convulsions and deaths occurred within 1 and $24 \mathrm{~h}$ respectively post pilocarpine injection, so we decided to record the phenotypes of the animals for $24 \mathrm{~h}$ after pilocarpine administration (Turski et al., 1983). At the end of observations, the survivors were killed by decapitation and their brains were dissected on ice to remove striatum for determinations of lipid peroxidation level and nitrite content. The pilocarpine group (P400) was constituted by those presented seizures and status epilepticus (SE) (Freitas et al., 2005).

The drug dosages of pilocarpine $(400 \mathrm{mg} / \mathrm{kg})$ and DMF ( $2 \mathrm{mg} / \mathrm{kg}$ ) were determined by previous study in our lab (Barros et al., 2007; Xavier et al., 2007) and the present study (data not shown). The drug doses used in this present study are not equivalent to those used by humans because rats have different metabolic rates.

\section{Behavioral effects and locomotor activity}

Behavioral screening of the rats was performed following parameters described by Almeida et al. (1999) and animals were observed at $24 \mathrm{~h}$ after i.p. administration of DMF of $P$. insignis ( $2 \mathrm{mg} / \mathrm{kg}$, i.p.). During $24 \mathrm{~h}$ were 
observed the occurrence of the following general signs (piloerection, prostration, writhing, evacuation, grooming, dyspnea, sedation, analgesia and palpebral ptosis).

Rats were divided into four groups of seven animals each. Vehicle received saline/Tween $80 \quad 0.5 \%$ (control group) and the tested groups were administered with DMF (2 $\mathrm{mg} / \mathrm{kg}$, i.p.). The spontaneous locomotor activity of the animals was assessed in a cage activity (50 $\mathrm{cm} \times 50 \mathrm{~cm} \times 50 \mathrm{~cm}$ ) after $24 \mathrm{~h}$ of treatment (Asakura et al., 1993).

Determinations of lipid peroxidation level in striatum of adult rats pretreated with DMF from $\mathrm{P}$. insignis prior to pilocarpine-induced seizures

For all experimental procedures, $10 \%(\mathrm{w} / \mathrm{v})$ homogenates of the area of the brain investigated were prepared for all groups. Lipid peroxidation levels in the DMF plus P400 group ( $n=6)$, P400 group $(n=6)$, DMF group $(n=6)$ and control animal $(n=9)$ were analyzed by measuring the thiobarbituric-acid-reacting substances in homogenates (Draper \& Hadley, 1990). Briefly, the homogenates were mixed with $1 \mathrm{~mL} 10 \%$ trichloroacetic acid and $1 \mathrm{~mL} 0.67 \%$ thiobarbituric acid, and were heated in a boiling water bath for $15 \mathrm{~min}$, and then butanol (2:1, $\mathrm{v} / \mathrm{v})$ was added to the solution. After centrifugation $(800$ $\mathrm{x} g, 5 \mathrm{~min}$ ), TBARS determinations were performed spectrophotometrically at $535 \mathrm{~nm}$ and expressed as nmol of malondialdehyde (MDA)/g wet tissue.

Determinations of nitrite content in striatum of adult rats pretreated with DMF from $\mathrm{P}$. insignis prior to pilocarpineinduced seizures

To determine nitrite contents of control group $(n=9)$, DMF plus P400 group $(n=6), P 400$ group $(n=6)$ and DMF group $(n=6)$, the $10 \%(w / v)$ homogenates were centrifuged $(800 \times \mathrm{g}, 10 \mathrm{~min})$. The supernatants were collected, and nitric oxide production was determined based on the Griess reaction (Green et al., 1981). Briefly, $100 \mu \mathrm{L}$ supernatant was incubated with $100 \mu \mathrm{L}$ of the Griess reagent at room temperature for $10 \mathrm{~min}$. Nitrite concentration was determined from a standard nitrite curve generated using $\mathrm{NaNO}_{2}$. Nitrite determinations were performed spectrophotometrically at $550 \mathrm{~nm}$ using a microplate reader and expressed as nM.

\section{Statistical analysis}

Results of latency to first seizure, locomotor activity and neurochemical alterations were compared by one-way analysis of variance (ANOVA) followed by Student-Newman-Keuls test $(p<0.05)$ (Graphpad program Intuitive, Software for Science, San Diego,
CA). The number of animals that seized and the number that survived were calculated as percentages (seizures percentage and survival percentage, respectively), and compared with a nonparametric test $\left(\chi^{2}\right)$.

\section{Results}

Behavioral alterations after pretreatment with DMF from P. insignis prior to pilocarpine-induced seizures

Pilocarpine induced the first seizure at $35.00 \pm 0.70$ min. All the animals studied showed generalized tonicclonic convulsions with SE, and 30\% survived the seizures. All animals pretreated with DMF from $P$. insignis were observed for $24 \mathrm{~h}$ before pilocarpine injection and their manifested alterations in behavior, such as peripheral cholinergic signs $(100 \%)$, tremors $(50 \%)$, staring spells, facial automatisms, wet dog shakes, rearing and motor seizures $(100 \%)$ developed progressively within $1-2 \mathrm{~h}$ into a long-lasting SE (100\%). Table 1 shows that DMF (2 mg/ $\mathrm{kg}$ ) administration before pilocarpine treatment reduced by $70 \%$ the percentage of animals that seized $(p<0.0001)$, increased latency $(341 \%)$ to the first seizure $(154.21 \pm 1.54$ $\min )(p<0.0001)$ and increased $(50 \%)$ the survival $(p<0.0001)$, when compared to the pilocarpine only group. None of the control animals (vehicle or dichloromethane fraction) showed seizures (Table 1).

Table 1. Effect of pretreatment with DMF from P. insignis prior to pilocarpine-induced seizures and lethality in adult rats.

\begin{tabular}{lccc}
\hline \multicolumn{1}{c}{ Groups } & $\begin{array}{c}\text { Latency to first seizures } \\
(\mathrm{min})\end{array}$ & $\begin{array}{c}\text { Percentage } \\
\text { seizures }\end{array}$ & $\begin{array}{c}\text { Percentage } \\
\text { survival }\end{array}$ \\
\hline Vehicle & 00 & 00 & 00 \\
P400 & $35.00 \pm 0.70$ & 100 & 30 \\
DMF + P400 & $154.21 \pm 1.54^{\mathrm{b}}$ & $30^{\mathrm{a}}$ & $80^{\mathrm{a}}$ \\
DMF & 00 & 00 & $100^{\mathrm{a}}$ \\
\hline
\end{tabular}

Male rats (250-280 g, 2 months old) were treated with a single dose of pilocarpine $(400 \mathrm{mg} / \mathrm{kg}$, i.p., $\mathrm{n}=12, \mathrm{P} 400)$, DMF group with DMF from $P$. insignis ( $2 \mathrm{mg} / \mathrm{kg}$, i.p., $\mathrm{n}=12)$ and the control animals with $0.9 \%$ saline/Tween $0.5 \%$ (i.p., $\mathrm{n}=12$ ). The DMF plus pilocarpine group was treated with DMF (2 mg/kg, i.p.) and $30 \mathrm{~min}$ before of administration received pilocarpine (400 mg/kg, i.p., $\mathrm{n}=12, \mathrm{DMF}+\mathrm{P} 400)$. Results for latency to first seizure are expressed as mean \pm S.E.M of the number of experiments shown in the table. Result for percentage seizures and percentage survival are expressed as percentages of the number of animals from each experimental group ( $n=12$ per group). The differences in experimental groups were determined by Analysis of Variance. ${ }^{\mathrm{a}} p<0.0001$ as compared with P400 group $\left(\chi^{2}\right.$-test). ${ }^{\mathrm{b}} p<0.0001$ as compared with $\mathrm{DMF}+\mathrm{P} 400$ group $\left(\chi^{2}\right.$-test $) .{ }^{c} p<0.0001$ as compared with P400 group (ANOVA and Student-Newman-Keuls as post hoc test). 
Locomotor activity after pretreatment with DMF from $\mathrm{P}$. insignis prior to pilocarpine-induced seizures

In P400 group was observed significant decreases of 9 and $21 \%$ of number of crossings and rearing, when compared to vehicle group, respectively. In dose of $2 \mathrm{mg} /$ $\mathrm{kg}$ of DMF caused significant increase of 11 and $7 \%$ of ambulation and rearing, when compared to P400 group, respectively. In addition, the pretreatment with DMF, $30 \mathrm{~min}$ before administration of pilocarpine increased number of crossings $(48 \%, p<0.001)$ and rearing $(49 \%$, $p<0.001)$ when compared to the P400 group (Figure 1). On the other hand, none of the control animals (vehicle or dichloromethane fraction) showed alterations in number of crossings and rearing (Figure 1).

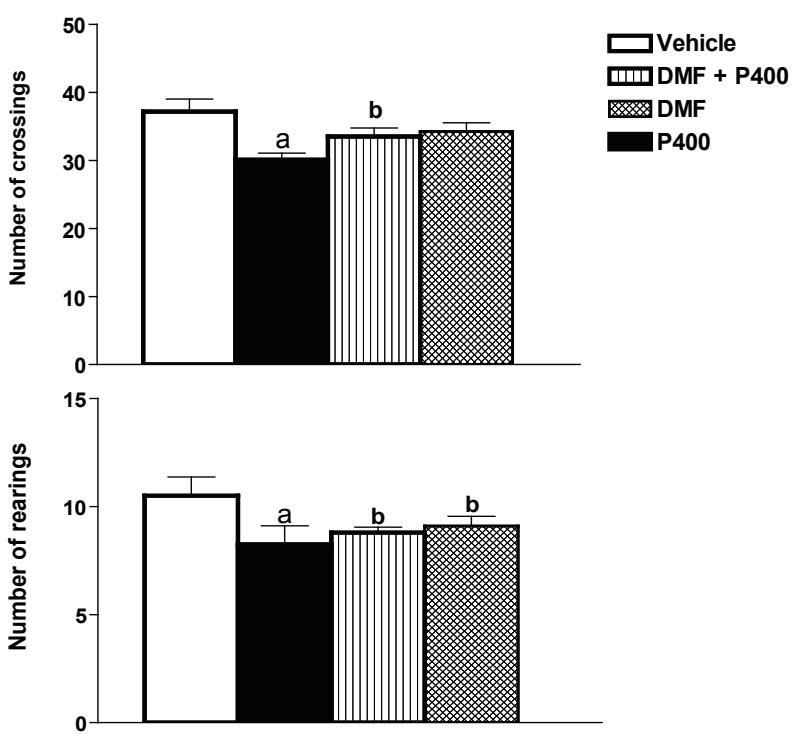

Figure 1. Effect of DMF from $P$. insignis on number of crossings and rearing of adult rats prior to pilocarpine-induced seizures. Male rats (250-280 g, 2 months old) were treated with a single dose of pilocarpine (400 mg/kg, i.p., $\mathrm{n}=6, \mathrm{P} 400)$, DMF group with DMF from P. insignis $(2 \mathrm{mg} / \mathrm{kg}$, i.p., $\mathrm{n}=6$, DMF group) and the control animals with vehicle (saline/ Tween 80 0.5\%, i.p., $\mathrm{n}=9$, control group). The DMF $+\mathrm{P} 400$ group was treated with DMF (2 mg/kg, i.p.) and $30 \mathrm{~min}$ before of administration received pilocarpine $(400 \mathrm{mg} / \mathrm{kg}$, i.p., $\mathrm{n}=6$, $\mathrm{DMF}+\mathrm{P} 400)$. Results are expressed as mean \pm S.E.M of the number of experiments shown in parenthesis. The differences in experimental groups were determined by Analysis of Variance (ANOVA). ${ }^{a} p<0.0001$ as compared with vehicle group (ANOVA and Student-Newman-Keuls as post hoc test). ${ }^{\mathrm{b}} p<0.0001$ as compared with P400 group (ANOVA and Student-NewmanKeuls as post hoc test).

Lipid peroxidation level and nitrite content in striatum of adult rats pretreated with DMF from $\mathrm{P}$. insignis prior to pilocarpine-induced seizures
Effects of DMF from $P$. insignis in lipid peroxidation and nitrite concentrations during seizures induced by pilocarpine are presented in Figure 2. Lipid peroxidation was markedly increased of in pilocarpine group in comparison with the corresponding values of the vehicle group. During acute phase of seizures induced by pilocarpine a significant increase $(89 \%)$ in thiobarbituricacid-reacting substances $(p<0.0001)$ was observed. Seizures induced by pilocarpine produced a significant increase in striatal nitrite content $(94 \%, p<0.0001$, Figure. $2)$. Rats pretreated with DMF showed decrease in lipid peroxidation level $(48 \%, \mathrm{p}<0.001)$ and nitrite content $(49 \%, p<0.001)$ when to compared with the pilocarpine group (Figure 2). In addition, the pretreatment with DMF, $30 \mathrm{~min}$ before administration of pilocarpine also reduced lipid peroxidation level $(94 \%, p<0.0001)$ and nitrite content $(51 \%, p<0.05)$ when compared to the vehicle group (Figure 2). On the other hand, none of the control animals (vehicle or dichloromethane fraction) showed changes in lipid peroxidation level and nitrite content (Figure 2).
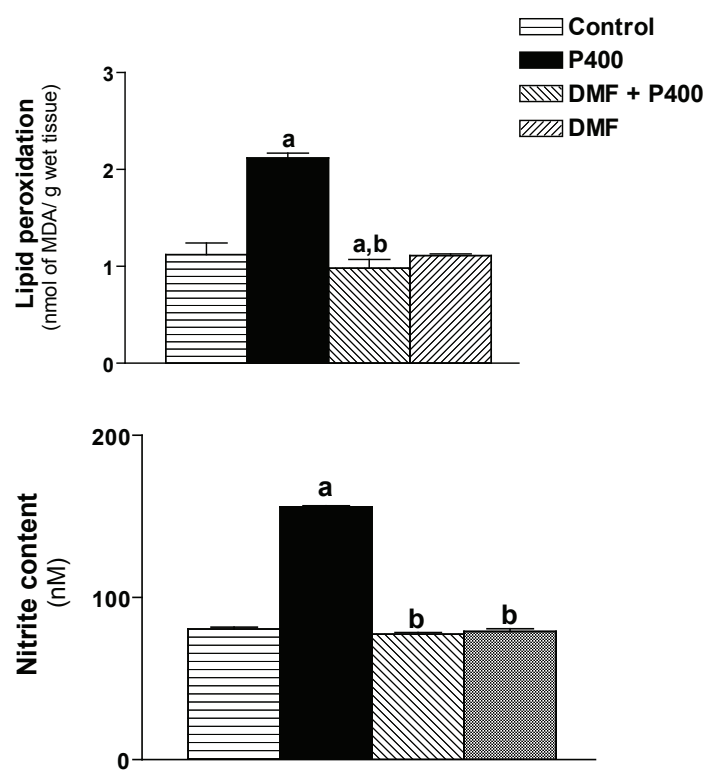

Figure 2. Effects of DMF on status of lipid peroxidation level and nitrite content in striatum of adult rats after seizures induced by pilocarpine. Male rats (250-280 g, 2 months old) were treated with a single dose of pilocarpine $(400 \mathrm{mg} / \mathrm{kg}$, i.p., $\mathrm{n}=6, \mathrm{P} 400)$, DMF group with DMF from $P$. insignis $(2 \mathrm{mg} / \mathrm{kg}$, i.p., $\mathrm{n}=6$, DMF group) and the control animals with vehicle (saline/Tween $800.5 \%$, i.p., $\mathrm{n}=9$, control group). The DMF + P400 group was treated with DMF (2 mg/kg, i.p.) and 30 min before of administration received pilocarpine (400 mg/ $\mathrm{kg}$, i.p., $\mathrm{n}=6, \mathrm{DMF}+\mathrm{P} 400)$. Results are expressed as mean \pm S.E.M of the number of experiments shown in parenthesis. The differences in experimental groups were determined by Analysis of Variance (ANOVA). ${ }^{a} p<0.0001$ as compared with vehicle (ANOVA and Student-Newman-Keuls as post hoc test). ${ }^{\mathrm{b}} p<0.0001$ as compared with P400 group (ANOVA and StudentNewman-Keuls as post hoc test). 


\section{Discussion}

In folk medicine of the Brazilian Northeast $P$. insignis seed oil's is used for treatment of eczemas, herpes, and diarrheas (Agra et al., 2007). In pharmacological behavioral screening, the animals treated with DMF of $P$. insignis showed increase of response to touches and increasing of motor activity. These data are indicative of stimulatory activity of the CNS (Almeida et al., 1999).

The possible CNS antioxidant and anticonvulsant activities of ethanol extract (Costa Júnior et al., 2010) and garcinielliptone FC (Costa Júnior et al., 2011) from $P$. insignis were investigated in vitro assays and in animal models. In present study we investigated effects of DMF from $P$. insignis in animal models. The mice treated with DMF presented behavioral alterations, such increased ambulation, palpebral ptosis, and stimulation. These behavioral changes suggest a possible effect on CNS; however, they are different to drugs that reduce the CNS activity (Morais et al., 2004; Netto et al., 2009).

Previous studies using low doses of ethanol extract and fractions from $P$. insignis demonstrated pharmacological activity in central nervous system, our experiments only with one dose of DMF present results anticonvulsant and antioxidant for this fraction. However, we need to investigate the same dose of DMF, as has central activity in other tests in vitro and in animal models of seizures (pentylenetetrazol and picrotoxin) to clarify the possible action mechanism of this fraction.

Dichloromethane fraction of $P$. insignis at the highest dose caused a significant increase of ambulation in the test of spontaneous movement after $24 \mathrm{~h}$ in the dose of $2 \mathrm{mg} / \mathrm{kg}$, corroborating with the hypothesis that DMF of $P$. insignis did not reduce the CNS activity. Our data suggest that DMF may be a stimulatory to the CNS, since studies shows that reduction of the ambulation of the animals is characteristic of depressant drugs (Carlini, 2003; Freire et al., 2006; Leite et al., 2008; Quintans Júnior et al., 2008b).

The increase of the locomotor activity was observed and it can be due to either through a stimulatory effect of the DMF of $P$. insignis on CNS or by absence of muscular relaxant activity in the periphery system. Our results indicate that DMF could possess a stimulator activity.

The molecular observations of epilepsy include the temporal correlation between free radical generation and the development of seizures in some pathological conditions, and the protective efficacy of antioxidant treatments against some types of seizures. P. insignis, one of the effective antioxidant, not only has antioxidant functions, but also has functions in pro-oxidant (Hosni et al., 2010; Lenta et al., 2007). Previous studies indicated that $P$. insignis has antioxidant activity in several animal models (Wu et al., 2005; Wu et al., 2008; Iinuma et al.,
1996; Gustafson et al., 1992). The effects of DMF of $P$. insignis leaves in CNS have not yet been determined, therefore, it would be important to conduct these studies to clarify its brain action mechanism in pilocarpine-induced seizures. In this study, we demonstrated a role of DMF from $P$. insignis against lipid peroxidation and nitrite formation produced by pilocarpine-induced seizures.

In the present study we investigated the influence of DMF from $P$. insignis on the level of lipid peroxidation and nitrite content in the rat striatum during pilocarpineinduced seizures. Generation of reactive oxygen species is currently viewed as one of the process through which epileptic activity exert their deleterious effects on brain (Rauca et al., 2004). These reactive oxygen species in the absence of an efficient defense mechanism cause peroxidation of membrane polyunsaturated fatty acids (Castagne et al., 1999). Brain is particularly susceptible to peroxidation due to simultaneous presence of high levels of polyunsaturated fatty acids and iron (Halliwell \& Gutteridge, 1999) which are the targets of free radical damage (Gottlieb et al., 2006; Halliwell \& Gutteridge, 1989). We showed the lipid peroxidation was rising in striatum homogenate of rats after $24 \mathrm{~h}$ of acute phase of seizures. The increase of lipid peroxidation was reflected by the rise of thiobarbituric-acid-reacting substances level which may be related to its intermediate free radicals formed during pilocarpine-induced seizures.

Literature has shown that pilocarpine-induced seizures led to changes in nitric oxide metabolism, and increased the production of its metabolites (nitrite and nitrate). The increased metabolites may interact with glutamatergic receptors to produce part of its stimulatory action on the central nervous system (Maczurek et al., 2008; Michiels et al., 1994). The reduction in nitrite content, after pretreatment with DMF from $P$. insignis, is most readily explained as a consequences of radical formation inhibiting, scavenges reactive oxygen species and lipid peroxidation products (Tejada et al., 2006).

Herein, we clearly showed that DMF from $P$. insignis decreased the frequency of pilocarpine-induced seizures and increased the survival rate. In our knowledge, these effects of DMF on lipid peroxidation and nitrite formation observed during acute phases of pilocarpineinduced seizures have not been reported before. Thus, these findings might have important implications for understanding the mechanism of epilepsy to promote new advances in the development of selective and targeted antiepileptic drugs. DMF from $P$. insignis might protect the striatum against neuronal damages regularly observed during seizures.

Our results confirm data previously reported in the literature that demonstrate anticonvulsant activity of ethanol extract of Hypericum perforatum in mice belonging to the same family of plant evaluated in this study (Hosseinzadeh et al., 2005; Vyawahare et al., 
2007). Further investigations of effects of DMF from $P$. insignis against necrosis, apoptosis and/or autophagy observed during the acute phase of this epilepsy model are in progress to confirm its neuroprotective effects.

\section{Acknowledgements}

The authors are grateful to Fundação de Amparo a Pesquisa do Estado do Piauí, Instituto Federal do Piauí, Conselho Nacional de Desenvolvimento Científico e Tecnológico.

\section{References}

Acuna UM, Jancovski N, Kennelly EJ 2009. Polyisoprenylated benzophenones from Clusiaceae: potential drugs and lead compounds. Curr Top Med Chem 9: 1560-1580.

Agra MF, Freitas PF, Barbosa-Filho JM 2007. Synopsis of the plants known as medicinal and poisonous in Northeast of Brazil. Rev Bras Farmacogn 17: 114-140.

Almeida RN, Falcão A, Diniz RST, Quintans-Júnior LJ, Polari RM, Barbosa-Filho JM, Agra MF, Duarte JC, Ferreira CD, Antoniolli AR 1999. Metodologia para avaliação de plantas com atividade no sistema nervoso central e alguns dados experimentais. Rev Bras Farm 80: 72-76.

Alves S, Jennings WG 1979. Volatile composition of certain Amazonian fruits. Food Chem 4: 149-159.

Asakura W, Matsumoto K, Ohta H, Watanabe H 1993. Effect of [alpha] 2-adrenergic drugs on REM sleep deprivationinduced increase in swimming activity. Pharmacol Biochem Behav 46: 111-115.

Barros DO, Xavier SML, Barbosa CO, Silva RF, Freitas RLM, Maia FD, Oliveira AA, Freitas RM, Takahashi RN 2007. Effects of the vitamin $\mathrm{E}$ in catalase activities in hippocampus after status epilepticus induced by pilocarpine in Wistar rats. Neurosci Lett 416: 227-230.

Bentes MHS, Serruya H, Rocha Filho GN, Godoy RLO, Silva Cabral JA, Soares Maia JG 1986. Estudo químico das sementes de bacuri. Acta Amazon 16: 363-368.

Bezerra DP, Moura DJ, Rosa RM, de Vasconcellos MC, e Silva AC, de Moraes MO, Silveira ER, Lima MA, Henriques JA, Costa-Lotufo LV, Saffi J 2008. Evaluation of the genotoxicity of piplartine, an alkamide of Piper tuberculatum, in yeast and mammalian V79 cells. Mutat Res 652: 164-174.

Carlini EA 2003. Plants and the central nervous system. Pharmacol Biochem Behav 75: 501-512.

Castagne V, Gautschi M, Lefevre K, Posada A, Clarke PGH 1999. Relationships between neuronal death and the cellular redox status. Focus on the developing nervous system. Prog Neurobiol 59: 397-423.

Chauhan AK, Dobhal MP, Joshi BC 1988. A review of medicinal plants showing anticonvulsant activity. $J$ Ethnopharmacol 22: 11-23.

Ciochina R, Grossman RB 2006. Polycyclic polyprenylated acylphloroglucinols. Chem Rev 106: 3963-3986.

Costa Júnior JS, Ferraz ABF, Filho BAB, Feitosa CM, Citó AMGL, Freitas RM, Saffi J 2011. Evaluation of antioxidant effects in vitro of Garcinielliptone FC (GFC) isolated from Platonia insignis Mart. $J$ Med Plants Res 52: 293-299.

Costa Júnior JS, Freitas RM, Citó AMGL, Henriques JAP, Saffi J 2010. Evaluation of effects of ethanolic extract (EE) from Platonia insignis Mart. on pilocarpine-induced seizures. J Biol Sci 10: 747-753.

Draper HH, Hadley M 1990. Malondialdehyde determination as index of lipid peroxidation. Methods Enzymol 186: 421-431.

Freire CMM, Marques MOM, Costa M 2006. Effects of seasonal variation on the central nervous system activity of Ocimum gratissimum L. essential oil. J Ethnopharmacol 105: 161-166.

Freitas RM, Vasconcelos SM, Souza FC, Viana GS, Fonteles MM 2005. Oxidative stress in the hippocampus after pilocarpine-induced status epilepticus in Wistar rats. FEBS J 272: 1307-1312.

Gottlieb M, Leal-Campanario R, Campos-Esparza MR, SánchezGómez MV, Alberdi E, Arranz A, Delgado-García JM, Gruart A, Matute C 2006. Neuroprotection by two polyphenols following excitotoxicity and experimental ischemia. Neurobiol Dis 23: 374-386.

Green LC, Tannenbaum SR, Goldman P 1981. Nitrate synthesis in the germfree and conventional rat. Science 212: 5658.

Gustafson KR, Blunt JW, Munro MHG, Fuller RW, McKee TC, Cardellina JH 1992. The guttiferones, HIV-inhibitory benzophenones from Symphonia globulifera, Garcinia livingstonei, Garcinia ovalifolia, and Clusia rosea. Tetrahedron 48: 10093-10102.

Halliwell B, Gutteridge JMC 1989. Lipid peroxidation: a radical chain reaction, free radicals in biology and medicine. Oxford: Clarendon Press, p. 188-276.

Halliwell B, Gutteridge JMC 1999. Free radicals in biology and medicine. London: Oxford Science Publications.

Hosni K, Msaâda K, Taârit MB, Hammami M, Marzouk B 2010. Bioactive components of three Hypericum species from Tunisia: A comparative study. Ind Crop Prod 31: 158163.

Hosseinzadeh H, Karimi G-R, Rakhshanizadeh M 2005. Anticonvulsant effect of Hypericum perforatum: role of nitric oxide. J Ethnopharmacol 98: 207-208.

Iinuma M, Tosa H, Tanaka T, Kanamaru S, Asai F, Kobayashi Y, Miyauchi K, Shimano R 1996. Antibacterial activity of some Garcinia benzophenone derivatives against methicillin-resistant Staphylococcus aureus. Biol Pharm Bull 19: 311.

Jackson B, Locksley HD, Scheinmann F 1966. Extractives from Guttiferae. Part I. Extractives of Calophyllum sclerophyllum Vesq. J Chem Soc C 1966: 178-181.

Leite MP, Fassin Jr J, Baziloni EMF, Almeida RN, Mattei 
R, Leite JR 2008. Behavioral effects of essential oil of Citrus aurantium L. inhalation in rats. Rev Bras Farmacogn 18: 661-666.

Lenta BN, Vonthron-Sénécheau C, Weniger B, Devkota KP, Ngoupayo J, Kaiser M, Naz Q, Choudhary MI, Tsamo E, Sewald N 2007. Leishmanicidal and cholinesterase inhibiting activities of phenolic compounds from Allanblackia monticola and Symphonia globulifera. Molecules 12: 1548-1557.

Maczurek A, Hager K, Kenklies M, Sharman M, Martins R, Engel J, Carlson DA, Munch G 2008. Lipoic acid as an anti-inflammatory and neuroprotective treatment for Alzheimer's disease. Adv Drug Deliv Rev 60: 14631470 .

Malawska B 2005. New anticonvulsant agents. Curr Top Med Chem 5: 69-85.

Marona H, Pekala E, Antkiewicz-Michaluk L, Walczak M, Szneler E 2008. Anticonvulsant activity of some xanthone derivatives. Bioorg Med Chem 16: 7234 7244.

Marona H, Pekala E, Filipek B, Maciag D, Szneler E 2001. Pharmacological properties of some aminoalkanolic derivatives of xanthone. Pharmazie 56: 567-572.

Michiels C, Raes M, Toussaint O, Remacle J 1994. Importance of Se-glutathione peroxidase, catalase, and $\mathrm{Cu} / \mathrm{Zn}-\mathrm{SOD}$ for cell survival against oxidative stress. Free Radical Biol Med 17: 235-248.

Morais L, Quintans-Júnior LJ, Franco CIF, Almeida J, Almeida RN 2004. Antiparkinsonian-like effects of Plumbago scandens on tremorine-induced tremors methodology. Pharmacol Biochem Behav 79: 745-749.

Netto SM, Warela RWB, Fechine MF, Queiroga MN, QuintansJúnior LJ 2009. Anxiolytic-like effect of Rauvolfia ligustrina Willd. ex Roem. \& Schult., Apocynaceae, in the elevated plus-maze and hole-board tests. Rev Bras Farmacogn 19: 888-892.

Ollis WD, Ramsay MVJ, Sutherland Stang IO 1965. The constitution of gambogic acid. Tetrahedron 21: $1453-$ 1470 .

Quintans Júnior LJ, Almeida J, Lima JT, Nunes XP, Siqueira JS, Oliveira LEG, Almeida RN, Athayde-Filho PF, BarbosaFilho JM 2008a. Plants with anticonvulsant properties: a review. Rev Bras Farmacogn 18: 798-819.

Quintans Júnior LJ, Souza TT, Leite BS, Lessa NMN, Bonjardim
LR, Santos MRV, Alves PB, Blank AF, Antoniolli AR 2008b. Phythochemical screening and anticonvulsant activity of Cymbopogon winterianus Jowitt (Poaceae) leaf essential oil in rodents. Phytomedicine 15: 619624.

Rauca C, Wiswedel I, Zerbe R, Keilhoff G, Krug M 2004. The role of superoxide dismutase and alpha-tocopherol in the development of seizures and kindling induced by pentylenetetrazol - influence of the radical scavenger alpha-phenyl-N-tert-butyl nitrone. Brain Res 1009: 203-212.

Taha AY, Burnham WM, Auvin S 2010. Polyunsaturated fatty acids and epilepsy. Epilepsia 51: 1348-1358.

Tejada S, Roca C, Sureda A, Rial RV, Gamundí A, Esteban S 2006. Antioxidant response analysis in the brain after pilocarpine treatments. Brain Res Bull 69: 587-592.

Turski WA, Cavalheiro EA, Schwarz M, Czuczwar SJ, Kleinrok Z, Turski L 1983. Limbic seizures produced by pilocarpine in rats: behavioural, electroencephalographic and neuropathological study. Behav Brain Res 9: 315335.

Vyawahare NS, Khandelwal AR, Batra VR, Nikam AP 2007. Herbal anticonvulsants. J Herbal Med Toxicol 1: 9-14.

Wu CC, Lu YH, Wei BL, Yang SC, Won SJ, Lin CN 2008. Phloroglucinols with prooxidant activity from Garcinia subelliptica. J Nat Prod 71: 246-250.

Wu CC, Weng JR, Won SJ, Lin CN 2005. Constituents of the pericarp of Garcinia subelliptica. J Nat Prod 68:11251127.

Xavier SM, Barbosa CO, Barros DO, Silva RF, Oliveira AA, Freitas RM 2007. Vitamin C antioxidant effects in hippocampus of adult Wistar rats after seizures and status epilepticus induced by pilocarpine. Neurosci Lett 420: 76-79.

\section{*Correspondence}

\section{Rivelilson Mendes de Freitas}

Laboratório de Pesquisa em Neuroquímica Experimental, Universidade Federal do Piauí

Campus Universitário Ministro Petrônio Portella, Curso de Farmácia, Bairro Ininga, 64049-550 Teresina-Piauí, Brazil rivelilson@pq.cnpq.br Tel.: +558632155870 